\title{
Inositol hexaphosphate hydrolysate competitively binds to AKT to inhibit the proliferation of colon carcinoma
}

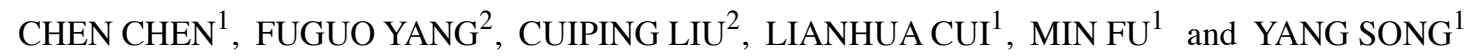 \\ ${ }^{1}$ Department of Public Health and ${ }^{2}$ School of Nursing, Qingdao University, Shibei, Qingdao, Shandong 266021, P.R. China
}

Received February 18, 2017; Accepted July 28, 2017

DOI: 10.3892/or.2017.5943

\begin{abstract}
Phytate, myto-inositol 1,2,3,4,5,6 hexaphosphate (IP6), is recognized as an anti-nutrition phytochemical for decades. Recently, numerous studies have indicated that IP6 and its hydrolysates could suppress colon oncogenesis. However, very little is known concerning the mechanism of IP6 hydrolysates in regulating colon oncogenesis. The aim of the present study was to identify the underlying relationship between IP6 hydrolysates and colon cancer. Three types of human colorectal cancer cells were utilized in the present study. The proliferation inhibition and migration assays were employed to reveal that IP6 hydrolysates inhibited the proliferation of SW620 cells. Real-time PCR, cell-based ELISA and the AKT inhibitor assay were utilized to reveal that 20 and $30 \%$ degree of hydrolysis hydrolysates of IP6 inhibited SW620 cell growth by inhibiting the activation of AKT protein. The docking simulation study revealed that IP4 and IP5 could inhibit the activation of AKT by binding to PIP3 receptor. Collectively, our results indicated that the IP6 hydrolysates inhibit SW620 cell proliferation; IP4 and IP5, the probable primary constituents of the 20-30\% degree of hydrolysis hydrolysates of IP6, inhibited the proliferation of SW620 cells by competitively inhibiting the AKT protein.
\end{abstract}

\section{Introduction}

According to 2012 Global Cancer Statistics, colorectal cancer has become the second leading cause of cancer-related deaths in developed countries (1). Colorectal cancer also poses a

Correspondence to: Professor Yang Song, Department of Public Health, Qingdao University, 38 Dengzhou Street, Shibei, Qingdao, Shandong 266021, P.R. China

E-mail: qdsongyang@126.com

Abbreviations: IP6, myto-inositol 1,2,3,4,5,6 hexaphosphate; DH, degree of hydrolysis; PI3K, phosphatidylinositol 3-kinase; AKT, protein kinase B; PH domain, pleckstrin homologydomain; PIP3, 3'-phosphorylated phosphoinositides 3,4,5-trisphosphate

Key words: phytate, IP6, hydrolysates, colorectal cancer, AKT, SW620 significant threat in developing countries. In China, colorectal cancer was the fifth leading cause of cancer-related deaths in 2015 (2). Compared with other forms of cancer, colorectal oncogenesis is highly correlated with diet (3). Various experts believe that phytate could be effective in preventing colon oncogenesis (4-7).

Phytate, myto-inositol 1,2,3,4,5,6 hexaphosphate (IP6), is ubiquitously distributed worldwide and exists in many types of plant-derived foods (8-10). When IP6 is ingested, it partially degraded by phytase into hydrolysates. Therefore, it is likely that the epithelial cells of the colon are exposed to the mixture of IP6 hydrolysates, but not IP6. Ishizuka et al revealed that the partially degraded IP6 products were responsible for the suppression of colon oncogenesis. It had been demonstrated that IP6 and IP6 hydrolysates were able to suppress HCT116 colon carcinoma cells (11). Based on these findings, we attempted to characterize the underlying antitumour mechanisms of IP6 hydrolysates.

According to our previous study, IP6 exerted inhibitory effects on HT-29 cells via the phosphatidylinositol 3-kinase $(\mathrm{PI} 3 \mathrm{~K}) /$ protein kinase B (AKT) signalling axis (10). The PI3K/AKT signalling axis is a major survival pathway. Abnormal activation of the PI3K/AKT pathway is frequently involved in the development and progression of various tumours, including colon cancer (12). In this pathway, AKT is a serine/threonine kinase and plays an essential role. It is activated by the 3'-phosphorylated phosphoinositides 3,4,5-trisphosphate (PIP3) protein and affects the activity of downstream factors, including mTOR, BAD and GSK3 $\beta$ (13-15). AKT contains the pleckstrin homology (PH) domain that has a high affinity for PIP3. In addition, IP6 hydrolysates also possess a similar PH domain as the PIP3 protein. Thus, based on the presumption of a similar structure and evidence from our previous study, we hypothesized that IP6 hydrolysates suppressed the proliferation of colon carcinoma cells through the PI3K/AKT pathway.

\section{Materials and methods}

Reagents. Inositol hexaphosphate (IP6) was purchased from Muster Biological Science Technology Company (Sichuan, China). Ascorbic acid, ammonium molybdate, antimony potassium tartrate, monopotassium phosphate, potassium peroxydisulfate and sulfuric acid were supplied by Sinopharm Chemical Reagent Co., Ltd. (Shanghai, China). Cell Counting Kit-8 (CCK-8) was purchased from Dojindo 
Molecular Technologies, Inc. (Kumamoto, Japan). RT-PCR was performed by a Two-Step RT-PCR QuantiScript RT kit (KR103) and a Real-Master/SYBR-Green kit (FR202) which were both purchased from the Tiangen Biotech (Beijing) Co., Ltd. (Beijing, China). The primers were designed using Primer Premier 5.0 (PREMIER Biosoft, Inc., Palo Alto, CA, USA) and Oligo 6.0 (Molecular Biology Insights, Inc., Colorado Springs, CO, USA) software and were synthesized by Shanghai Biological Engineering Company (Shanghai, China). The cell-based ELISA kits were supplied by ImmunoWay Biotechnology Company (Plano, TX, USA).

Hydrolysis curve. The hydrolysis curve assays were performed using the total phosphorus ammonium molybdate spectrophotometric method. Different concentrations of IP6 $(0.25$, $1,4,16,64,250,1,000,4,000,16,000$ and 64,000 $\mu \mathrm{g} / \mathrm{ml})$ were suspended in water, and potassium peroxydisulfate $(50 \mathrm{~g} / \mathrm{l})$ was added for digestion. After digestion, molybdate and ascorbic acid were added to the solution and allowed to develop for $15 \mathrm{~min}$. The absorbance of the solution at $690 \mathrm{~nm}$ was determined using a microplate reader. Each experiment was repeated three times. The optical density (OD) was recorded to draw the hydrolysis curve.

Determination of the IP6 hydrolysis rate. Forty milligrams IP6 (final concentration, $200 \mu \mathrm{g} / \mathrm{ml}$ ) and $6 \mu \mathrm{g}$ of phytase were suspended in $200 \mathrm{ml}$ of $50 \mathrm{mM}$ sodium acetate (pH 5.5) and incubated at $37^{\circ} \mathrm{C}$ for $1-8 \mathrm{~h}$. Two types of phytase (EcAppA from Escherichia coli and phytase from wheat) were assessed in the present study. The pretreated hydrolysis solutions were then evaluated using the total phosphorus ammonium molybdate spectrophotometric method aformentioned without digestion. The degree of hydrolysis (DH) of IP6 was calculated as follows:

$$
\begin{array}{ll}
\mathrm{DH}=\mathrm{C}_{1} / \mathrm{C}_{2} & \\
\mathrm{C}_{1} \longrightarrow & \text { Hydrolysis phosphorus, } \mathrm{m} / \mathrm{l} \\
\mathrm{C}_{2} & \text { Total phosphorus, } \mathrm{m} / \mathrm{l}
\end{array}
$$

IP6 and its hydrolysates ranging from 10 to $90 \%$ DH were concentrated via vacuum freeze dehydration and stored in a cold dark place.

Cell culture. SW620, HCT116 and HT29 cells obtained from the Cell Bank of the Chinese Academy of Sciences (Shanghai, China) were grown in RPMI-1640 medium supplemented with $10 \%$ fetal bovine serum (FBS). The cells were cultured in the absence of antibiotics. The cells were grown at $37^{\circ} \mathrm{C}$ in a $5 \%(\mathrm{v} / \mathrm{v}) \mathrm{CO}_{2}$ atmosphere in a humidified incubator. Decreased serum media [25 ml/l phosphate-buffered saline (PBS)] was used for all experiments.

Cell proliferation assay. The cell proliferation assay was performed in order to investigate the time- and concentration-dependent effects of IP6 on the growth of SW620,HCT116 and HT29 cells. Logarithmic phase cells $\left(1 \times 10^{4}\right.$ cells/well $)$ were seeded onto 96-well tissue culture plates in $5 \% \mathrm{CO}_{2}$ at $37^{\circ} \mathrm{C}$. After $12 \mathrm{~h}$, the medium was replaced with fresh medium containing 0 (control group), 1, 10 or $100 \mu \mathrm{g} / \mathrm{ml}$ of IP6 hydrolysates, and the cells were incubated in $\mathrm{CO}_{2}$ at $37^{\circ} \mathrm{C}$ for $48 \mathrm{~h}$.
The CCK- 8 reagent was added to the cells, and the plates were incubated at $37^{\circ} \mathrm{C}$ for $2 \mathrm{~h}$. After incubation, the absorbance was assessed at $490 \mathrm{~nm}$ using a microplate reader. A decrease in absorbance was considered to reflect a loss of cell viability. The cell viability rate was calculated by comparison with the control group. Each experiment was repeated three times.

Cell migration assays. To quantify the migratory potential of the hydrolysates-treated SW620 cells; the cells were plated in culture, placed on a 24-well plate at high density and grown with complete culture medium until confluence. After carefully removing the inserts, two cell monolayers separated by a cell-free gap of $\sim 500 \mu \mathrm{m}$ were created. The cells were washed with PBS and incubated with the corresponding treatments: $10 \mu \mathrm{g} / \mathrm{ml}$ IP6, 20\% DH hydrolysates, 30\% DH hydrolysates and $90 \% \mathrm{DH}$ hydrolysates in triplicate for $48 \mathrm{~h}$. After the treatment time, each well was captured with a digital camera coupled to an inverted microscope. The distance of the gap in each group was assessed using Image-Pro Plus (Media Cybernetics, Inc., Rockville, MD, USA).

Real-time PCR. Using the TRIzol reagent kit, total RNA was extracted from the SW620 cells treated with 1, 10 and $100 \mu \mathrm{g} / \mathrm{ml}$ of IP6. The mRNA levels were determined using an Eppendorf protein nucleic acid detector. Total RNA $(2 \mu \mathrm{g})$ was reverse-transcribed using the PrimeScript RT reagent kit, followed by reverse transcription using the Bio-Rad MyCycler PCR system. The sense and antisense primer sequences and the PCR product sizes are shown in Table I. The PCR was performed in a $20 \mu \mathrm{l}$ total reaction volume system. The cycling conditions were as follows: for PI3K, 50 cycles at $95^{\circ} \mathrm{C}$ for $2 \mathrm{~min}, 95^{\circ} \mathrm{C}$ for $15 \mathrm{sec}$ and $60^{\circ} \mathrm{C}$ for $20 \mathrm{sec}$. For AKT, 50 cycles at $95^{\circ} \mathrm{C}$ for $2 \mathrm{~min}, 95^{\circ} \mathrm{C}$ for $15 \mathrm{sec}$ and $60^{\circ} \mathrm{C}$ for $20 \mathrm{sec}$. For $\mathrm{BAD}, 50$ cycles of $95^{\circ} \mathrm{C}$ for $2 \mathrm{~min}, 95^{\circ} \mathrm{C}$ for $15 \mathrm{sec}$ and $60^{\circ} \mathrm{C}$ for $20 \mathrm{sec}$. The comparative $\mathrm{Ct}$ formula $2^{-\Delta \Delta \mathrm{Ct}}$ was used to calculate the relative gene expression levels.

Cell-based ELISA. The cultured SW620 cells were seeded onto 96 -well plates at $5 \times 10^{4}$ cells $/ \mathrm{cm}^{2}$. When appropriate, the cells were serum-starved for $4 \mathrm{~h}$ and stimulated with IP6 hydrolysates for $10 \mathrm{~min}$. After stimulation, the cells were fixed with $4 \%$ formaldehyde in PBS for $20 \mathrm{~min}$ at room temperature and washed three times with washing buffer. The cells were then incubated in quench buffer for $20 \mathrm{~min}$, washed three times in washing buffer, blocked with $10 \%$ fetal calf serum buffer for $1 \mathrm{~h}$ and incubated overnight with various dilutions of a primary antibody at $4^{\circ} \mathrm{C}$. The following day, the cells were washed three times with washing buffer for $5 \mathrm{~min}$ and incubated with a secondary antibody (peroxidase-conjugated goat anti-rabbit antibody; dilution 1:100) in PBS and Triton with $5 \%$ BSA for $1 \mathrm{~h}$ at room temperature and then washed three times with washing buffer for 5 min and twice with PBS. Subsequently, the cells were incubated with $50 \mu$ l of substrate development solution for $15 \mathrm{~min}$ at room temperature in the dark. The reaction was stopped with $50 \mu \mathrm{l}$ of stop solution. The absorbance was assessed, and the SD values were determined using a microplate reader.

AKT-inhibited assay. Similar to the cell proliferation assay, logarithmic phase cells $\left(1 \times 10^{4}\right.$ cells/well) were seeded onto 
Table I. Real-time-PCR primer sequences and product sizes.

\begin{tabular}{|c|c|c|}
\hline Gene & Primer sequence & $\begin{array}{c}\text { Product } \\
\text { size } \\
\text { (bp) }\end{array}$ \\
\hline$\beta$-actin & $\begin{array}{ll}\text { F } & \text { 5'-CCTGGCACCCAGCACAAT-3' } \\
\text { R } & \text { 5'-GGGCCGGACTCGTCATAC-3' }\end{array}$ & 144 \\
\hline $\mathrm{PI} 3 \mathrm{~K}$ & $\begin{array}{l}\text { F 5'-CTTTTCCCCACAAATCCTCA-3' } \\
\text { R 5'-CAGTTGCCCCTATCCCCTAT-3' }\end{array}$ & 117 \\
\hline AKT & $\begin{array}{ll}\text { F } & \text { 5'-AGCGGAAGGAGGTGAAGAAT-3' } \\
\text { R } & \text { 5'-GGGAAAACGGAGACTTAGGG-3' }\end{array}$ & 126 \\
\hline BAD & $\begin{array}{ll}\text { F } & \text { 5'-GGGTTCTGAGGGGAGACTGA-3' } \\
\text { R } & \text { 5'-CTCTGGGCTGTGAGGACAAG-3' }\end{array}$ & 211 \\
\hline
\end{tabular}

F, forward; R, reverse; PI3K, phosphatidylinositol 3-kinase.

96-well tissue culture plates in $5 \% \mathrm{CO}_{2}$ at $37^{\circ} \mathrm{C}$. After $12 \mathrm{~h}$, the medium was replaced with fresh medium containing $0.1 \mu \mathrm{mol} / 1$ of MK2206 ( $\mathrm{IC}_{50}$ concentration in SW620 cells) and $10 \mu \mathrm{g} / \mathrm{ml}$ of IP6, and the cells were incubated in $\mathrm{CO}_{2}$ at $37^{\circ} \mathrm{C}$ for $48 \mathrm{~h}$. The CCK- 8 reagent was added to the cells, and the plates were incubated at $37^{\circ} \mathrm{C}$ for $2 \mathrm{~h}$. After incubation, the absorbance at $490 \mathrm{~nm}$ was determined using a microplate reader. A decrease in the absorbance was considered to reflect a loss of cell viability. Each experiment was repeated three times.

Molecular docking simulation study. A docking study was performed to examine the qualified binding positions of IP6 hydrolysates against AKT. The crystallographic structure of AKT with its ligand was obtained from the RCSB Protein Data Bank (PDB ID, 4EKL). The main protein structure was obtained by removing the $4 \mathrm{EKL}$ ligand (2S)-2-(4-chlorophenyl)-1-\{4-[(5R,7R)-7-hydroxy5-methyl-6,7-dihydro- 5H-cyclopenta[d)pyrimidin-4-yl) piperazin-1-yl\}-3-(propan-2-ylamino)propan-1-one and the water molecules using AutoDock 4.2. After removing the heteroatoms and adding the hydrogen atoms, the protein was suitable for docking simulation with respect to obtaining the best ligand binding results. Thirteen two-dimensional structures of the IP6 hydrolysate constituents were drawn using ChemDraw 8.0. All two-dimensional IP6 hydrolysates were transformed into three-dimensional structures using Avogadro 1.0.3 and converted into PDB files with Open Babel 2.3.2. AutoDock 4.2, an open-source program, was used for the docking simulation. Grid boxes $126 \times 126 \times 126$ points in size with spacing of $0.375 \mathrm{~A}^{\circ}$ between the points were generated to cover almost the entire favourable protein binding site. The $\mathrm{X}, \mathrm{Y}$ and $\mathrm{Z}$ centres were 22.15, 2.53 and 15.74, respectively. The binding aspects of the AKT residues and their corresponding binding affinity scores were regarded as the best molecular interactions. The results were analysed using UCSF Chimera and LigPlot (v.1.4.5). The two-dimensional images of the IP6 hydrolysate-AKT interactions were calculated using LigPlot v.1.4.5 (European Bioinformatics Institute, London, England). All
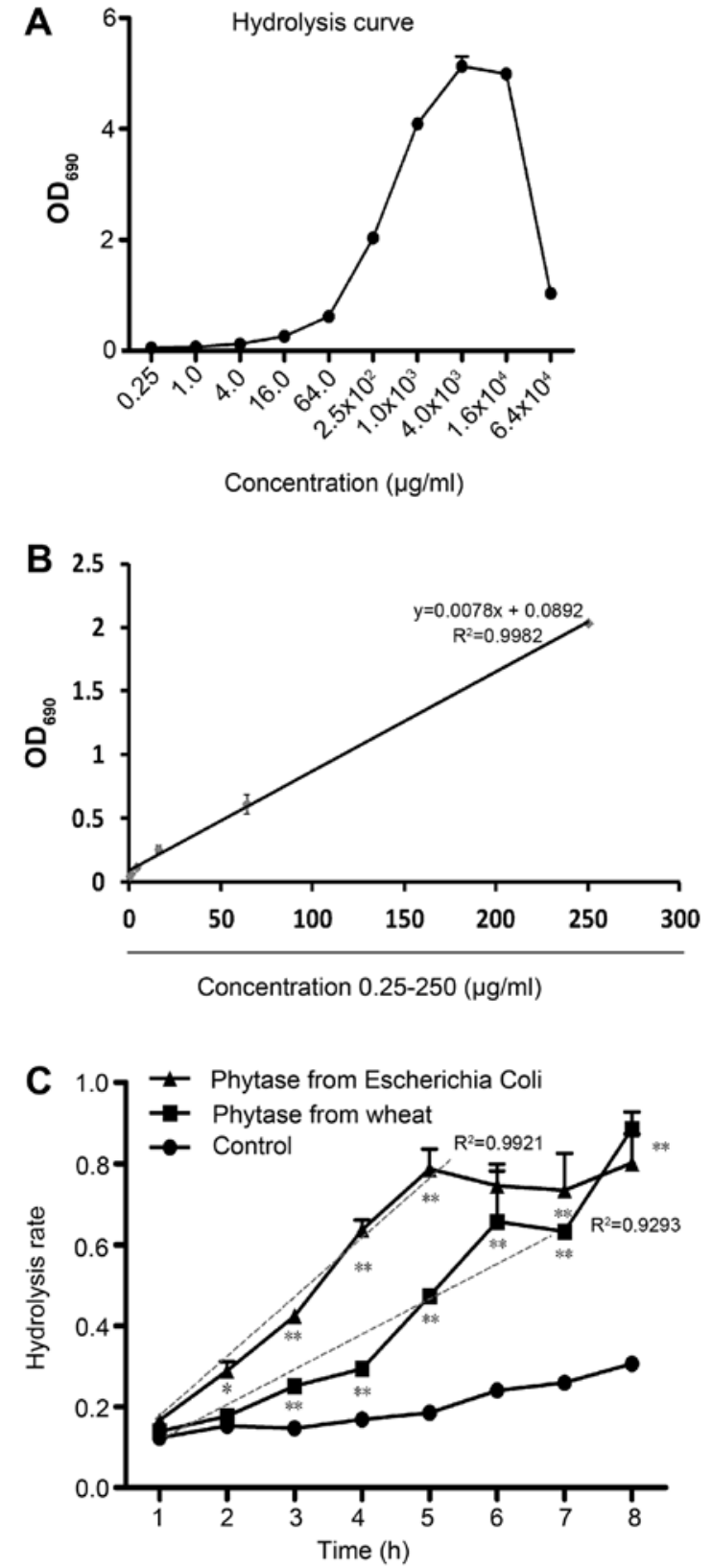

Figure 1. Hydrolysis curve and hydrolysis efficiency of phytases from wheat or Escherichia coli. (A and B) The hydrolysis curve was drawn by the content of total phosphorus. Different concentrations of IP6 were completely digested by potassium peroxydisulfate. (C) The hydrolysis efficiency curve of phytases from wheat or Escherichia coli. The free phosphorusime point was assessed in the solution by the phosphorus ammonium molybdate spectrophotometric method each hour for $8 \mathrm{~h}$. The results are expressed as the mean \pm SD of at least three independent experiments; ${ }^{*} \mathrm{P}<0.05,{ }^{* *} \mathrm{P}<0.01$. IP6, inositol hexaphosphate; SD, standard deviation.

docking simulations were performed using an Intel Core TM i5-2520 M CPU @ 2.50 GHz with Windows 8.1 and a 64-bit operating system.

Statistical analysis. All reactions were performed for three times and each independent experiment was carried out in duplicate or triplicate according to the manufacturer's instructions. A completely randomized design (CRD) was used for the statistical analysis of the physical and chemical data. All data were subjected to analysis of variance (ANOVA), and 

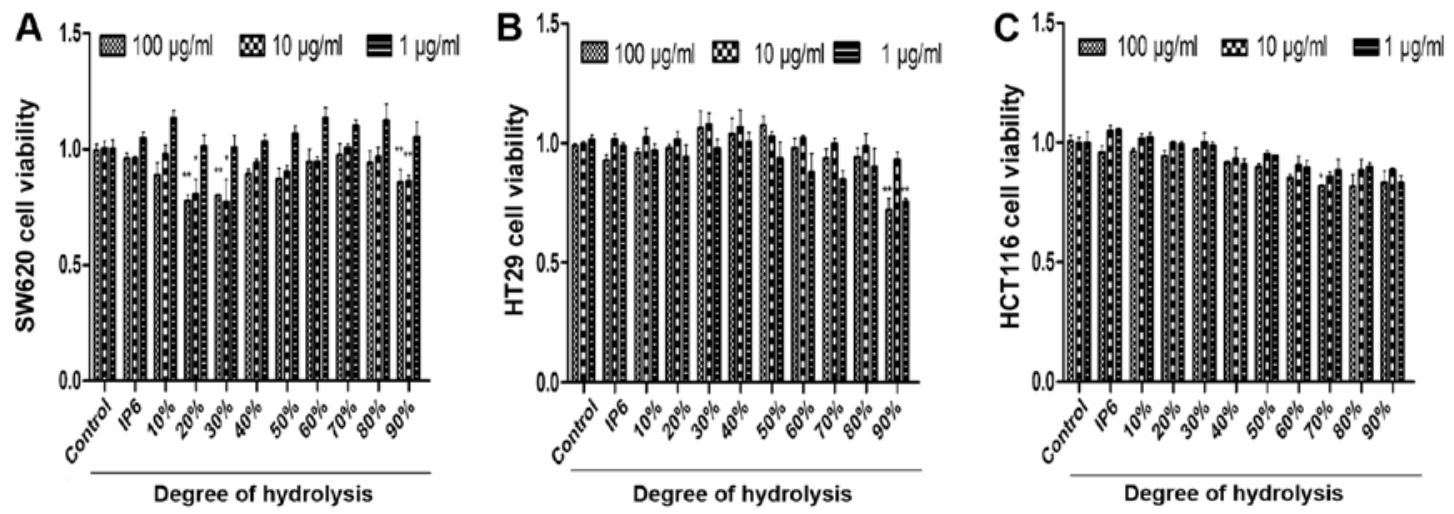

Figure 2. Inhibitory curve of colorectal cancer SW620, HCT116 or HT29 cells treated with IP6 hydrolysates. (A) SW620, (B) HT29 and (C) HCT116 cells were treated with 1,10 or $100 \mu \mathrm{g} / \mathrm{ml}$ of IP6 hydrolysates for $48 \mathrm{~h}$. The cell viability was assessed by cell proliferation assay. The results of the experiment were independently carried out in triplicate. All values are expressed as the mean $\pm \mathrm{SD} ;{ }^{*} \mathrm{P}<0.05,{ }^{* *} \mathrm{P}<0.01$. IP6, inositol hexaphosphate.

A

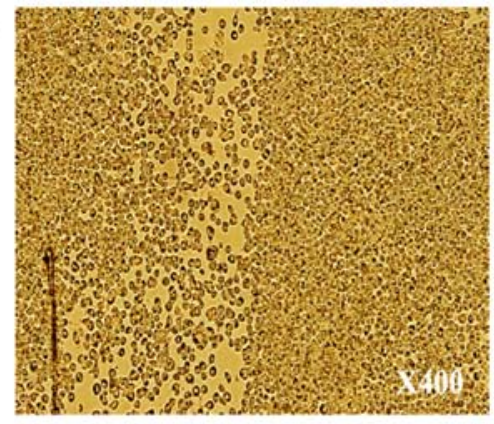

C

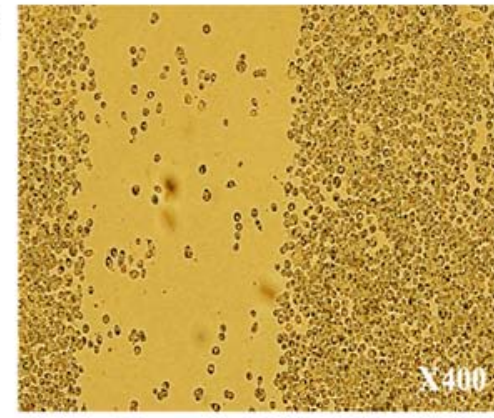

E

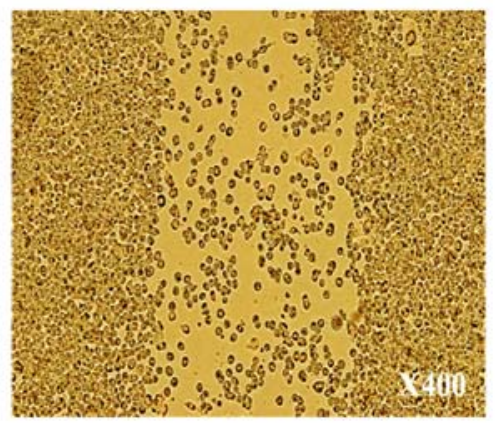

B

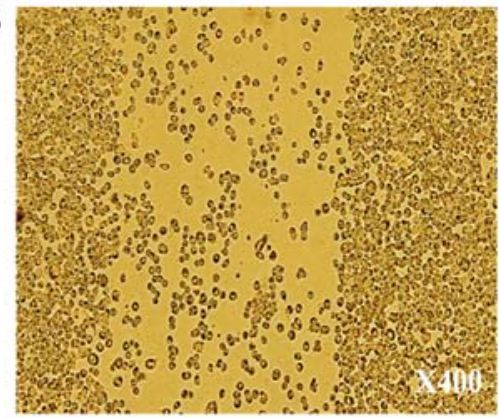

D

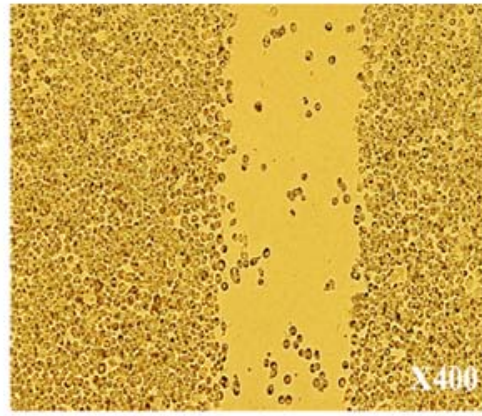

$\mathbf{F}$

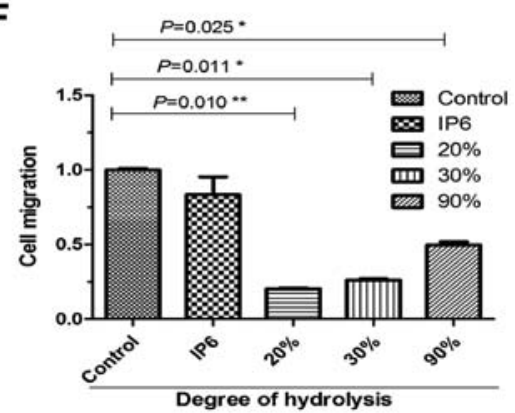

Figure 3. The cell migration of SW620 cells treated with IP6 or DH hydrolysates. Cells were placed in a 24-well plate overnight. The cells were scraped with a 200- $\mu 1$ tip, then washed with PBS to remove unattached cells and changed to new media containing (A) 0 , (B) $10 \mu \mathrm{g} / \mathrm{ml}$ of IP6, (C) $10 \mu \mathrm{g} / \mathrm{ml}$ of $20 \% \mathrm{DH}$ hydrolysates, (D) $10 \mu \mathrm{g} / \mathrm{ml}$ of 30\% DH hydrolysates or (E) $10 \mu \mathrm{g} / \mathrm{ml}$ of $90 \%$ DH hydrolysates for $48 \mathrm{~h}$. The images were captured using a digital camera under an inverted microscope. The distance of the gap in each group was assessed using Image-Pro Plus. (F) The distance was expressed as the means \pm SD; " $P<0.05$, ${ }^{* *} \mathrm{P}<0.01$, when compared with the negative control group. IP6, inositol hexaphosphate; DH, degree of hydrolysis.

mean comparisons were carried out using Duncan's multiple range test. Statistically analysed using SPSS version 19.0 (SPSS for windows; SPSS, Inc., Chicago, IL, USA). P $<0.05$ was considered statistically significant.

\section{Results}

Comparison of the hydrolysis efficiencies of different phytases. To determine the proper IP6 hydrolysis condition, 
a series of IP6 concentrations ranging from $0.25 \mu \mathrm{g} / \mathrm{ml}$ to $64 \mathrm{mg} / \mathrm{ml}$ were tested in the present study. All the free phosphoric acid was released after IP6 was fully hydrolyzed by potassium peroxydisulfate. The free phosphoric acid was detected with a microplate reader. According to Fig. 1A, when the IP6 concentration was increased to $16 \mathrm{mg} / \mathrm{ml}$, the total reaction system reached its limit and the OD 690 value markedly decreased. According to Fig. 1B, the free phosphoric acid concentration released from IP6 at concentrations ranging from 0.25 to $250 \mu \mathrm{g} / \mathrm{ml}$ exhibited suitable reaction efficiencies $\left(y=0.0078 x+0.0892, R^{2}=0.9980\right)$. To analyze the effects of different phytases on IP6 hydrolysis, we assessed the two phytases, one extracted from wheat and one from Escherichia coli. Free phosphorus of IP6 was determined per hour for $8 \mathrm{~h}$. Compared with $37^{\circ} \mathrm{C}$ control group, the two phytases showed significantly enhanced hydrolysis effects. However, the hydrolysis efficiency of the wheat phytase was low and unstable $\left(y=0.0805 x+0.0026, R^{2}=0.9293\right)$, shown in Fig. 1C. In contrast, the hydrolysis efficiency of EcAppA was high and stable $\left(y=0.1507 x-0.0027, R^{2}=0.9921\right)$. These results indicated that the EcAppA phytase was more suitable for preparing IP6 hydrolysates. Using the hydrolysis curve and the proper phytase, we were able to assess the dynamic hydrolysis condition and calculate the IP6 hydrolysis rate. We concentrated 10-90\% DH IP6 hydrolysates via vacuum freeze dehydration.

IP6 hydrolysates inhibits of SW620, HCT116 and HT29 cell growth. After preparing the different DH hydrolysates, we used the cell proliferation assay to identify the inhibitory effects of three main colorectal cancer cell lines with various concentrations. We were surprised to find that the SW620 cells were very sensitive to 20,30 and $90 \%$ DH hydrolysates. DH hydrolysates $(20,30$ and $90 \%)$ in 100 and $10 \mu \mathrm{g} / \mathrm{ml}$ concentration groups exhibited better tumour-suppressor activity compared with the $1 \mu \mathrm{g} / \mathrm{ml}$ concentration group (Fig. 2A). HT29 cells were not sensitive to the majority of the hydrolysates of each concentration tested. Differences were observed in two groups which were $90 \% \mathrm{DH}$ hydrolysates in the 1 and $100 \mu \mathrm{g} / \mathrm{ml}$ concentration groups (Fig. 2B). HCT116 cells were not sensitive to the majority of the hydrolysates either. The $70 \% \mathrm{DH}$ hydrolysates $(100 \mu \mathrm{g} / \mathrm{ml})$ was the only group which suppressed cell proliferation (Fig. 2C). The results demonstrated that the inhibitory effects of DH hydrolysates of IP6 were effective in SW620 cells.

IP6 and its hydrolysates suppresses the migration of SW620 cells. To ascertain the results of the cell proliferation assay; we used a migration assay on SW620 cells. After being loaded with $10 \mu \mathrm{g} / \mathrm{ml}$ of IP6, 20\% DH, 30\% DH and 90\% DH IP6 hydrolysates, the motility of the cells was markedly altered (Fig. 3). It should be noted that SW620 cell proliferation and motility was inhibited after treatment with 20,30 and 90\% DH IP6 hydrolysates.

IP6 hydrolysates do not alter the mRNA expression of PI3K, $A k t$, and BAD in the SW620 cells. To explore the effects of IP6 hydrolysates on SW620 cells, we measured the expression of PI3K, AKT and BAD mRNA using real-time PCR. Compared with the control group, the expression of PI3K, AKT and BAD
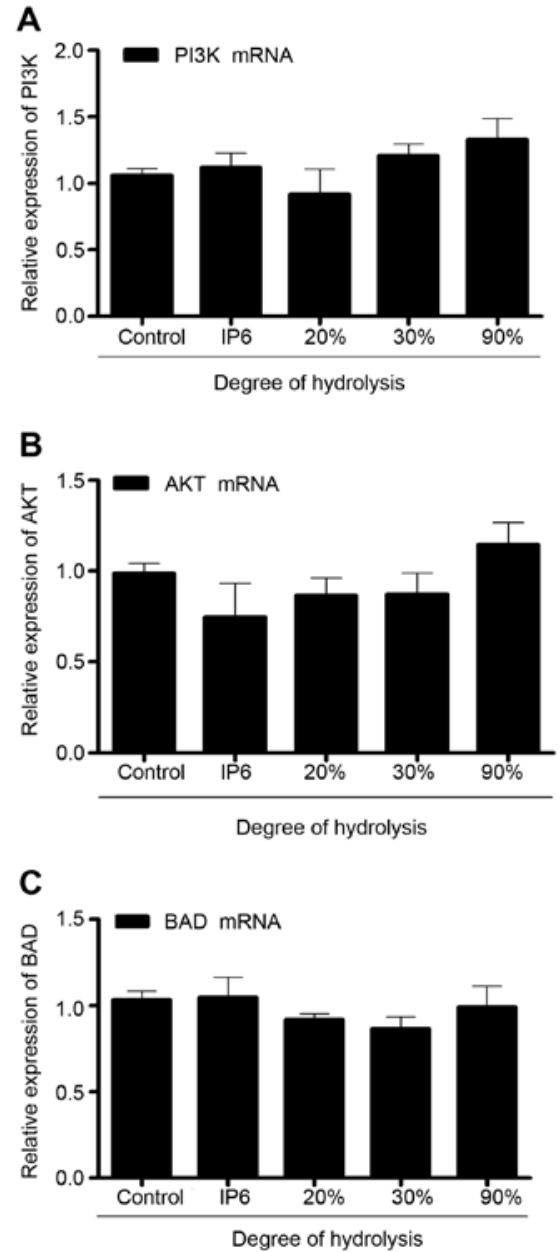

Figure 4. mRNA expression of PI3K, Akt and BAD in SW620 cells treated with IP6 or DH hydrolysates. SW620 cells were treated with $10 \mu \mathrm{g} / \mathrm{ml}$ of IP6 or different concentrations of DH hydrolysates for $48 \mathrm{~h}$. The total RNA was extracted using TRIzol reagents. The mRNA expression of (A) PI3K, (B) Akt and $(C)$ BAD was determined by real-time PCR. The results are expressed as the means \pm SD from three independent experiments. IP6, inositol hexaphosphate; DH, degree of hydrolysis.

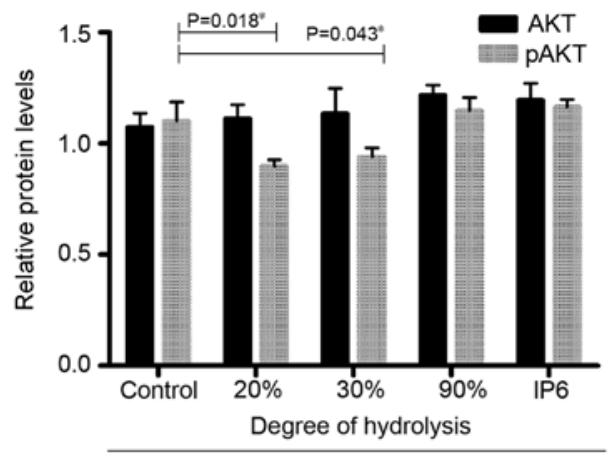

Figure 5. Expression of AKT in SW620 cells treated with IP6 and DH hydrolysates. SW620 cells were treated with $10 \mu \mathrm{g} / \mathrm{ml}$ of IP6 or different concentrations of DH hydrolysates for $48 \mathrm{~h}$. The expression of AKT and pAKT was assessed using a cell-based ELISA assay. The results of experiment were independently carried out in triplicate. All values are expressed as the mean $\pm \mathrm{SD} ;{ }^{*} \mathrm{P}<0.05$. IP6, inositol hexaphosphate; $\mathrm{DH}$, degree of hydrolysis.

mRNA in the SW620 cells did not exhibit any differences. Results (Fig. 4) indicated that IP6 hydrolysates did not affect the expression of PI3K, AKT and BAD mRNA. 
Table II. Molecular interactions between the IP4 isomers, IP5 and the AKT protein activator PIP3.

\begin{tabular}{|c|c|c|c|c|}
\hline Compounds & $\begin{array}{l}\text { Binding } \\
\text { energy }\end{array}$ & $\begin{array}{l}\text { No. of } \\
\text { H-bonds }\end{array}$ & $\mathrm{H}$-bond interacting residues & Van der Waals interacting residues \\
\hline $1,2,3,4$ IP4 & 6.85 & 4 & $\begin{array}{l}\text { Lys284:HZ1 Lys284:HZ2 } \\
\text { Lys214:HZ2 Arg 174:HH11 }\end{array}$ & Try 175 Try 176 \\
\hline $1,2,3,5$ IP5 & 6.56 & 5 & $\begin{array}{l}\text { Lys284:HZ1 Lys284:HZ2 } \\
\text { Tyr176:OH Arg174:HH11 } \\
\text { Lys214:HZ2 }\end{array}$ & Try 175 Try 176 \\
\hline $1,2,4,5$ IP6 & 6.02 & 3 & $\begin{array}{l}\text { Tyr175:Hz1 Lys214:HZ2 } \\
\text { Tyr175:HN }\end{array}$ & $\begin{array}{l}\text { Ala212 Try } 176 \text { Glu228 } \\
\text { Leu213 Arg174 }\end{array}$ \\
\hline IP5 & 5.88 & 4 & $\begin{array}{l}\text { Lys214:HZ2 Lys214:HZ3 } \\
\text { Arg174:HH11 Lys284:HZ1 }\end{array}$ & Ala212 Ser478 Ala476 \\
\hline PIP3 & 10 & 1 & Lys214:HZ2 & $\begin{array}{l}\text { Arg174 Ser478 Ala476 Gln203 } \\
\text { Gln471 Asn204 Arg } 200\end{array}$ \\
\hline
\end{tabular}

IP6, inositol hexaphosphate.

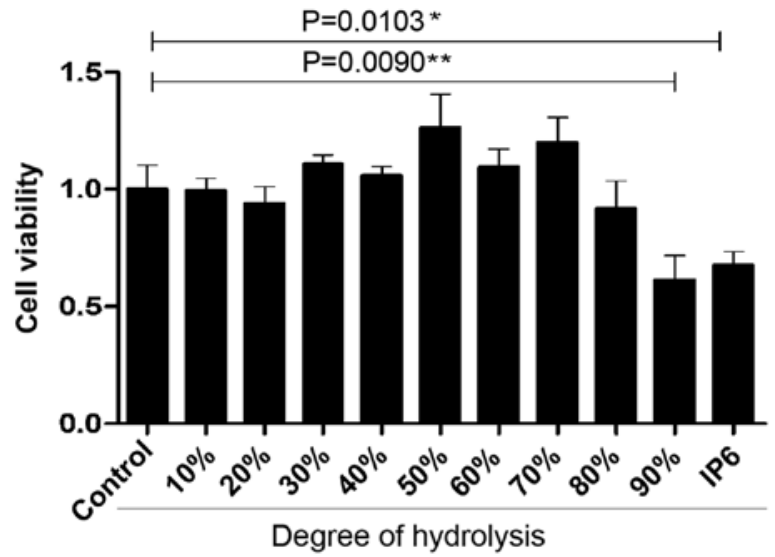

Figure 6. IP6 hydrolysates plus with MK2206 inhibit the cell growth of SW620 for $48 \mathrm{~h}$. Cells were treated with IP6 hydrolysates $(10 \mu \mathrm{g} / \mathrm{ml})$ and MK2206 $(0.1 \mu \mathrm{M})$ concurrently. The cell viability was assessed using a cell proliferation assay. The results are expressed as the means \pm SD from three independent experiments; ${ }^{*} \mathrm{P}<0.05,{ }^{* *} \mathrm{P}<0.01$. IP6, inositol hexaphosphate.

IP6 hydrolysates affect the expression of Akt and pAkt in SW620 cells. Next, using cell-based ELISA, we investigated whether the IP6 hydrolysate treatments affected the expression of proteins related to the PI3K/AKT pathway. The results (Fig. 5) indicated that after hydrolysate treatment (20, 30 and 90\%), the protein expression of total Akt did not change. In contrast, the protein expression of pAKT changed significantly in the 20 and $30 \%$ DH groups. Based on these results, IP6 hydrolysate treatment inhibited the expression of pAKT in the SW620 cells.

IP6 hydrolysates inhibit SW620 cell proliferation when the AKT protein is inhibited. According to our results, certain IP6 hydrolysates inhibited the proliferation of SW620 cells with MK2206. As shown in Fig. 6, after treating SW620 cells with MK2206, 10, 20, 30, 40, 50, 60 and 70\% DH hydrolysates did not inhibit cell proliferation. SW620 cells were treated with 80 and 90\% DH hydrolysates and IP6 plus MK2206 exhibited a slight decrease in the growth rate of SW620 cells.
IP4 and IP5 bind to the AKT protein. Next, we employed molecular docking studies to obtain the predictions of the protein-ligand interaction geometries of the IP6 hydrolysates and the AKT protein. Thirteen IP6 hydrolysates were used as control ligands for validation in AutoDock 4.2. The docking scores of the IP6 hydrolysates with the interacting residues, the number of hydrogen bonds formed between the interacting residues and the residues exhibiting van der Waals interacting force are shown in Table II. The activity of the thirteen IP6 hydrolysates against AKT was correlated with the binding energy, and the number of hydrogen bonds formed at the active site. The thirteen hydrolysates were arranged to dock with the AKT protein; however, only IP5 and 3 of the IP4 isomers could bind to the AKT protein (Fig. 7). Inositol and the IP1, IP2 and IP3 isomers could not bind to the AKT protein.

\section{Discussion}

In the present study, IP6 hydrolysates exerted inhibitory effects on SW620 cells, and certain hydrolysates inhibited AKT activation as AKT protein inhibitors. We first examined the effects of 10-90\% DH hydrolysates on three colorectal tumour cells (HT29, HCT116 and SW620) by cell proliferation assays. DH hydrolysates (20, 30 and 90\%) significantly inhibited the proliferation of SW620 cells. The data from the wound healing assay confirmed the results of the cell proliferation assay in SW620 cells. Thus, we cautiously speculated that metastatic SW620 tumour cells may be susceptible to IP6 hydrolysates.

Next, as aforementioned, IP6 hydrolysates possess an analogous domain as PIP3. Thus, we wondered whether IP6 hydrolysates could affect the activation of the AKT protein. A real-time PCR assay was utilized to clarify whether IP6 hydrolysates affected the mRNA expression of AKT. After treatment with IP6 hydrolysates, AKT and its upstream factor, PI3K, and downstream factors, BAD, did not exhibit any differences with the control group in SW620 cells. Since IP6 hydrolysates could not affect the expression of AKT mRNA, we investigated the AKT protein expression using cell-based ELISA. Cell-based ELISA is a new protein detection technique which permits 
A

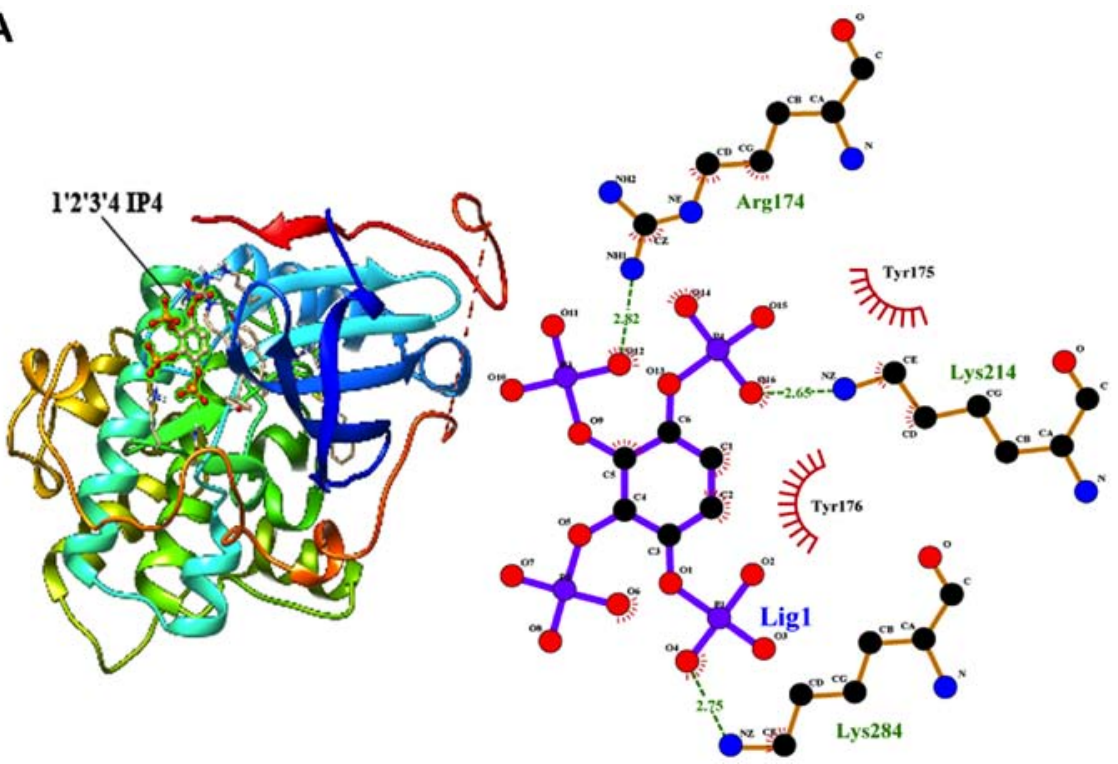

B
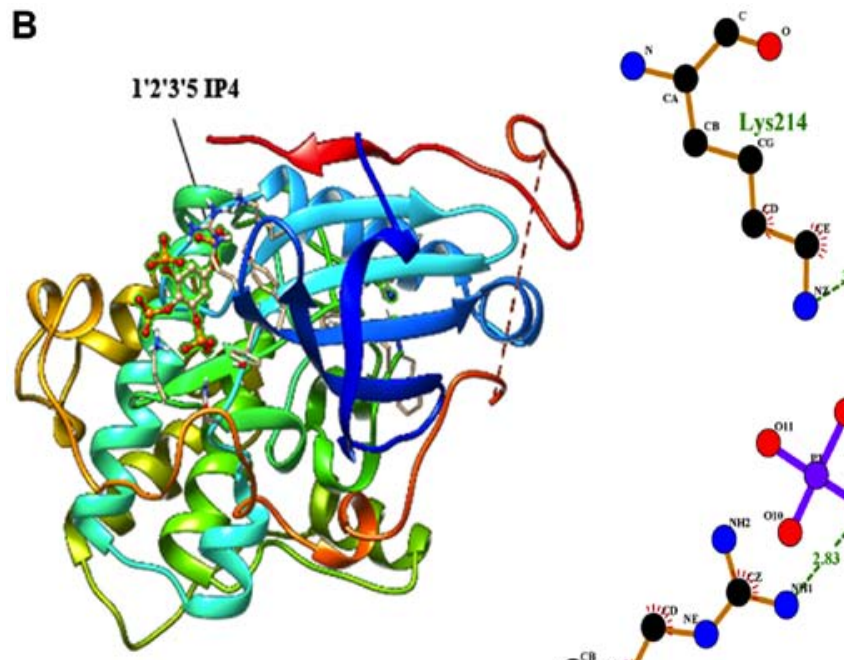

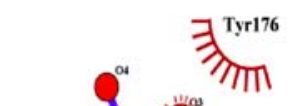
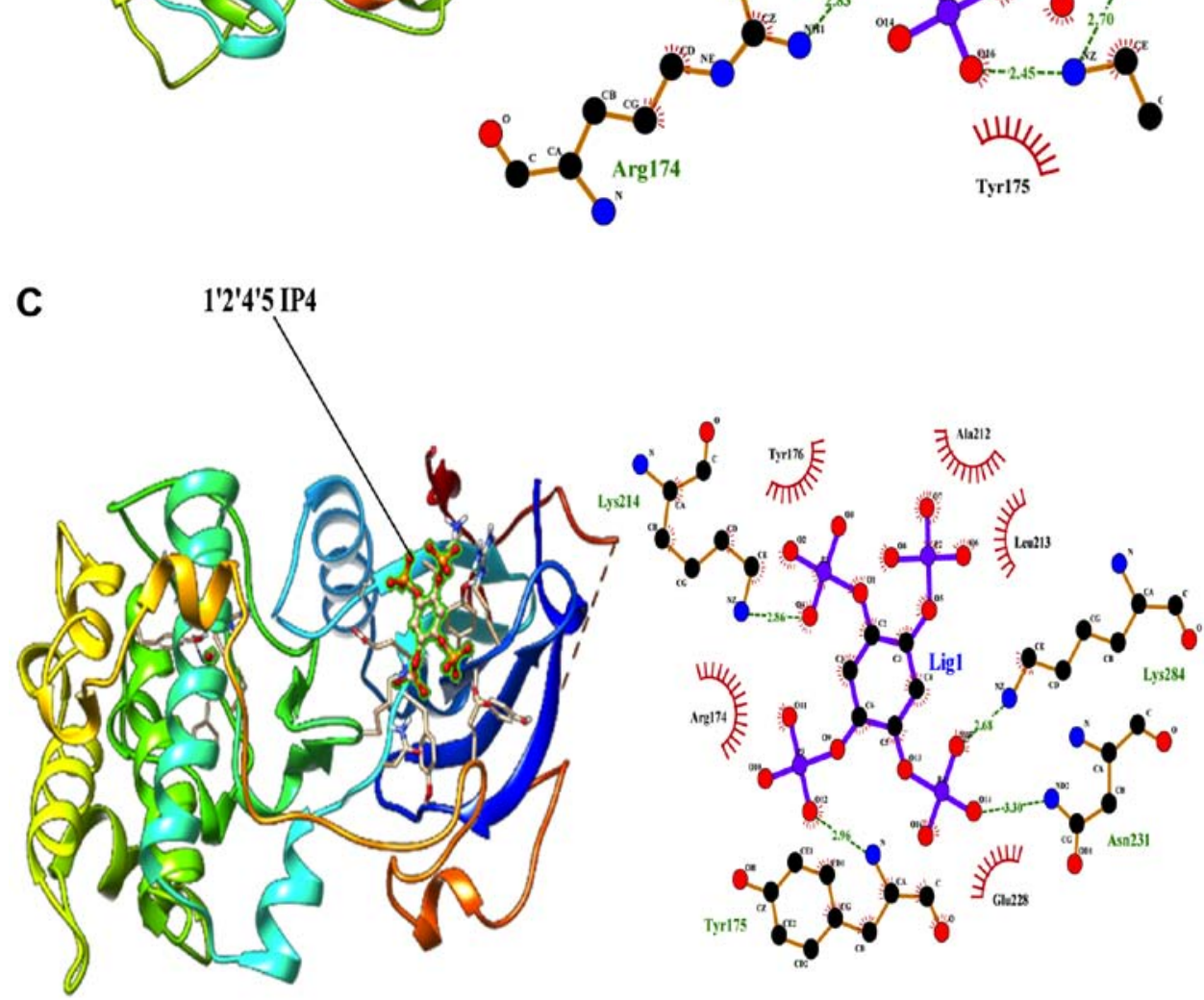

Figure 7. IP4s, IP5 and PIP3 bind to the active site of AKT. The structural ligands were analysed by AutoDock 4.2 to depict the docked conformation of these compounds with AKT (PDB ID, 4EKL). Hydrogen bonding and hydrophobic interactions for the (A) 1'2'3'4IP4, (B) 1'2'3'5IP4 and (C) 1'2'4'5IP4. 

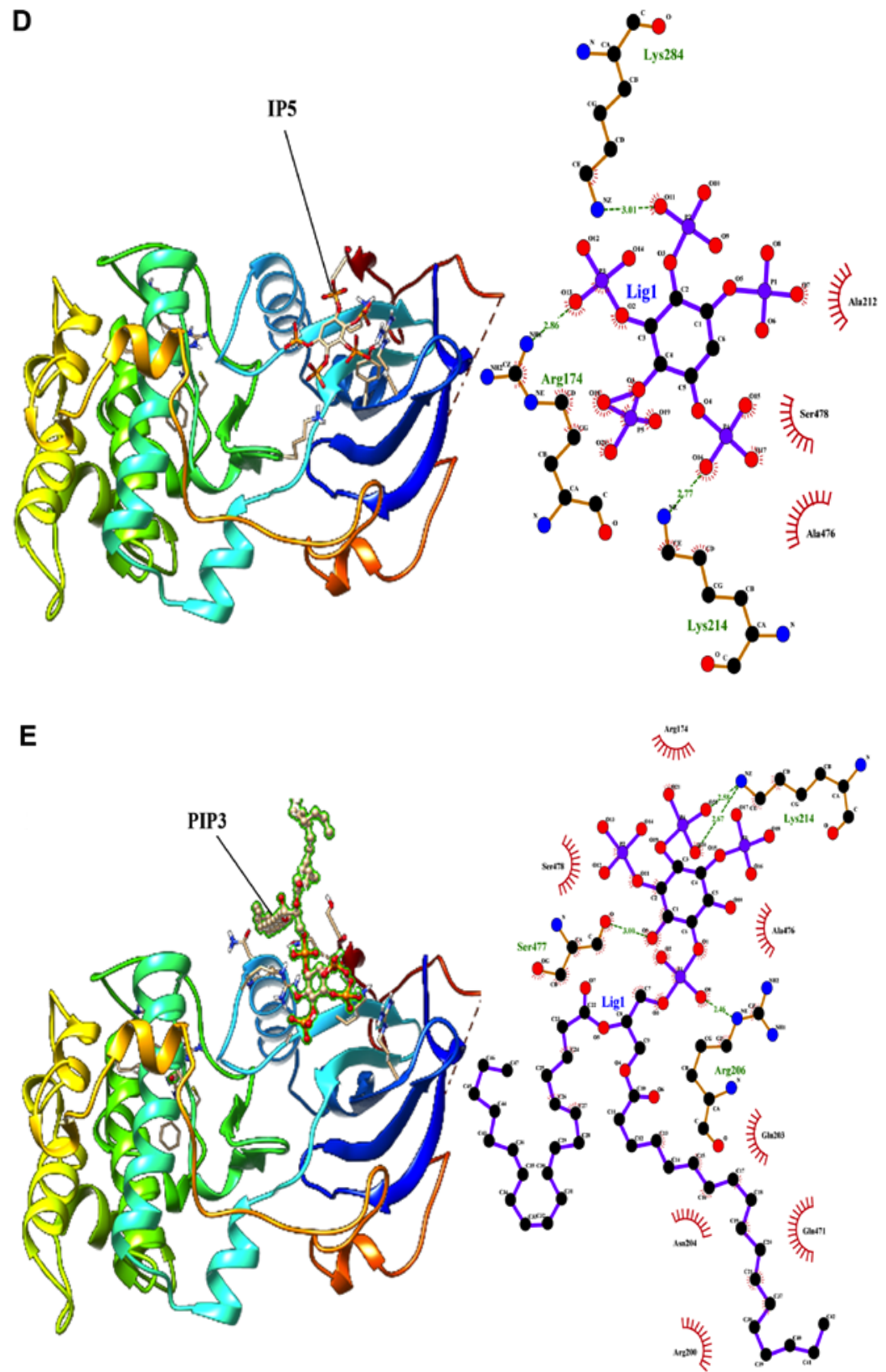

Figure 7. Continued. IP4s, IP5 and PIP3 bind to the active site of AKT. (A-E) The structural ligands were analysed by AutoDock 4.2 to depict the docked conformation of these compounds with AKT (PDB ID, 4EKL). Hydrogen bonding and hydrophobic interactions for the (D) IP5 and (E) PIP3.

direct detection of cell proteins without extraction. This technique has significant advantages in phosphoprotein analysis. Compared with traditional western blot assay, cell-based ELISA detects the expression of phosphoproteins quickly and decreases the unnecessary phosphoproteins lost from extraction and phosphatise degradation. Thus, we chose cell-based ELISA for pAKT and total protein detection. In Fig. 5, the total AKT protein did not exhibit any difference in each group, but the 20 and $30 \%$ DH hydrolysates inhibited the activation of the AKT protein by inhibiting the expression of the pAKT protein. The results indicated that certain IP6 hydrolysates at 20 and 30\% DH may have a close relationship with the activation of AKT protein.

The result of cell-based ELISA was insufficient to conclude that hydrolysates may induce changes in the AKT protein. Hence, the classical AKT inhibitor MK2206 was utilized in an AKT inhibition assay to study the relationship between hydrolysates and the AKT protein. In the present study, 20 and $30 \%$ DH hydrolysates did not suppress the proliferation of SW620 cells when the AKT protein was inhibited. It was proposed that 20-30\% DH hydrolysates inhibited tumour proliferation which was closely related to the AKT protein. In contrast, $90 \%$ DH hydrolysates continually inhibited cell growth. This implied that $90 \%$ DH hydrolysates inhibited SW620 cell growth through a different mechanism.

Lastly, the molecular docking simulation study was performed to predict the binding energies and the specific binding site of hydrolysates on AKT and to identify the interacting residues using AutoDock software. According to our data, IP5 and the isomers of IP4 exhibited a similar binding pattern as PIP3. IP1, IP2, IP3 and IP6 could not bind to the AKT protein. According to a study from Yuyinng, when 
the DH reached 16.67 and $33.36 \%$, the main contents of the hydrolysates of IP6 were IP5 and IP4 (16). Hence we carefully deduced that the main contents of the 20-30\% DH IP6 hydrolysates were IP4 isomers and IP5. The results of the docking simulation study confirmed that IP4 isomers and IP5 could attach to the binding area of AKT and inhibit the activation of the AKT protein. This finding explained why 20 and 30\% DH hydrolysates inhibited the activation of the AKT protein and slowed the tumour growth rate. Collectively, with the data of the PCR analysis, the AKT inhibited assay and the molecular docking simulation study we confirmed our hypothesis that IP6 hydrolysates, IP5 and IP4, contain a similar structural domain with PIP3, and may bind to the PIP3 receptor of AKT. These hydrolysates occupied the receptor, but could not exhibit any biological functions. Therefore, we concluded that 20 and $30 \%$ DH of IP6 hydrolysates inhibited the activation of the AKT protein to suppress the proliferation of SW620 cells, and these hydrolysates inhibited AKT protein activation mainly through competitive inhibition to the PIP3 receptor.

Although our results revealed that IP6 hydrolysates act as an AKT protein inhibitor, there were a few limitations. Separation of the unique hydrolysate was the first issue. With the help of our laboratory colleagues, over a period of two years, we attempted to separate the unique hydrolysate and its isomers by several different methods; we utilized classic chromatography, colorimetric, HPLC, paper chromatography, thin layer chromatography, NMR, dialysis membrane and other methods (17-24). Despite our best efforts, we were unsuccessful. However, we are not discouraged. We are going to deal with this problem in the future and we appreciate the researchers who motivated us. Although we were unable to separate the unique hydrolysate, the mixture of IP6 hydrolysates was still worth being investigated. When IP6 was obtained from the ingestion of food, it was hydrolysed into a group of hydrolysates by intestinal bacteria phytases. These hydrolysate mixtures may just be the exposure substances for colon epithelial cells. Therefore, studying the IP6 hydrolysate mixtures is biologically relevant. DH hydrolysates (90\%) was the second issue. This is a very special mixture of the present study. These hydrolysates in $90 \% \mathrm{DH}$ inhibited the proliferation of SW620 cells, but did not inhibit AKT activation (shown in Fig. 2). According to the results reported by Dinicola et al, inositol efficiently slowed the rate of differentiation and the dissemination of breast cancer cells (25-30). According to IP6 hydrolysis progression, the more free phosphates of IP6 hydrolysed, the less binding phosphates remained on the inositol molecular skeleton. According to the study of Fu et al, when the DH reached to 83 and 100\%, the main contents of the hydrolysates of IP6 were IP1 and inositol. We speculate that the main content of the $90 \% \mathrm{DH}$ hydrolysates was inositol. DH hydrolysate $(90 \%)$ worked as an antitumour agent in a different manner compared with the 20 and 30\% DH hydrolysates which may be investigated in our future study.

The present study, was greatly motivated by previous studies which investigated the relationship between IP6 and its hydrolysates in colon cancer. However, there were some differences that should be mentioned. According to Ishizuka et al, IP6 and its hydrolysates were able to suppress HCT116 colon cells. They also indicated that partially degraded IP6 products inhibited cell proliferation via different mechanisms from those of intact IP6 (11). Suzuki et al believed that IP6 hydrolysates induced F-actin ring formation, the key factor in the phytatemediated anticancer function in HT29 cells (23). Their results were similar to our findings; we all contended that partly hydrolysed IP6 inhibited the colon cell growth. However, there were still some differences that remained. Their studies suggested that IP6 and IP6 hydrolysates inhibited HT29 and HCT116 cells, but we did not find any differences in these two cell lines. The differences may be derived from the different intervention concentrations. The concentrations in the study of Ishizuka et al and Suzuki and Hara, were 2.1-4.1 g/l and $66-3,000 \mathrm{mg} / 1$, separately $(11,23)$. According to the study of Ishizuka $e t a l$, the hydrolysates could not affect the protein phosphorylation when the concentration did not reach $1 \mathrm{mM}$ (300-500 mg/l) in HT29 cells. This concentration was higher than the one we used (1-100 mg/l) in the present study. In vitro, results may markedly change when the concentrations are different. The concentrations were 3-40 times different when comparing the present study to theirs, which explained why the differences in the HCT116 and HT29 cells could not be observed in the present study.

In addition to the lower hydrolysates and IP6 concentrations used in the present study, we also investigated the whole DH hydrolysates of IP6 against colon cancer for the first time. The mixture of IP6 hydrolysates is the absorbed form of IP6 in the colon. The intestine epithelial cells may not be exposed to IP6 actually, however, they are commonly exposed to the IP6 hydrolysed mixture. We confirmed that the anticancer properties of IP6 are primarily due to its hydrolysates which competitively inhibited the activation of the AKT protein. The present study first used the molecular docking simulation method to indicate that IP4 and IP5 may be effective components of IP6 hydrolysates. In the past few years, IP3 has been recognized as the main component of all IP6 hydrolysates. However, according to our molecular docking simulation data, IP4 and IP5 also play an important role in preventing oncogenesis.

Moreover, our results indicated that IP6 hydrolysates could be a protective factor against colon carcinoma. The protective functions may be significantly dependent on the condition of colon bacteria. Intestinal flora disturbances may decrease colon phytase secretion, which may hinder the IP6 hydrolysates to prevent oncogenesis. Hence, we hypothesize that the enteric flora disturbances may be a new mechanism employed in colon oncogenesis.

In conclusion, IP6 hydrolysates were able to suppress SW620 colon carcinoma cells and inhibited the activation of the AKT protein. The 20 and 30\% DH IP6 hydrolysates suppressed the proliferation and inhibited the AKT protein. IP6 has been known to be an anti-nutrition phytochemical for decades. Our findings in the present study suggest that IP6 and its hydrolysates may be a valuable agent for cancer prevention and treatment, however further investigation is required.

\section{Acknowledgements}

The present study was supported by grants from The National Natural Science Foundation of China (no. 81373001). 


\section{References}

1. Torre LA, Bray F, Siegel RL, Ferlay J, Lortet-Tieulent J and Jemal A: Global cancer statistics, 2012. CA Cancer J Clin 65: 87-108, 2015.

2. Chen W, Zheng R, Baade PD, Zhang S, Zeng H, Bray F, Jemal A, Yu XQ and He J: Cancer statistics in China, 2015. CA Cancer J Clin 66: 115-132, 2016.

3. Siegel R, Desantis C and Jemal A: Colorectal cancer statistics, 2014. CA Cancer J Clin 64: 104-117, 2014.

4. Yang GY and Shamsuddin AM: IP6-induced growth inhibition and differentiation of HT-29 human colon cancer cells: Involvement of intracellular inositol phosphates. Anticancer Res 15: 2479-2487, 1995.

5. Shamsuddin AM, Vucenik I and Cole KE: $\mathrm{IP}_{6}$ : A novel anticancer agent. Life Sci 61: 343-354, 1997.

6. Somasundar P, Riggs DR, Jackson BJ, Cunningham C, Vona-Davis L and McFadden DW: Inositol hexaphosphate (IP6): A novel treatment for pancreatic cancer. J Surg Res 126: 199-203, 2005.

7. Rizvi I, Riggs DR, Jackson BJ, Ng A, Cunningham C and McFadden DW: Inositol hexaphosphate (IP6) inhibits cellular proliferation in melanoma. J Surg Res 133: 3-6, 2006.

8. Shamsuddin AM: Metabolism and cellular functions of IP6: A review. Anticancer Res 19: 3733-3736, 1999.

9. Parfiniewicz B, Pendzich J, Kapral M, Bednarek I and Weglarz L: The influence of TNF-alpha on concentration of soluble adhesion molecules in cultures of HT-29 cells exposed to inositol hexaphosphate. Acta Pol Pharm 69: 1291-1297, 2012.

10. Liu G, Song Y, Cui L, Wen Z and Lu X: Inositol hexaphosphate suppresses growth and induces apoptosis in HT-29 colorectal cancer cells in culture: PI3K/Akt pathway as a potential target. Int J Clin Exp Pathol 8: 1402-1410, 2015.

11. Ishizuka S, Saitoh K, Suzuki T, Lee JS and Hara H: A partially degraded product of phytate suppresses the proliferation of HCT116 colorectal cancer cells. Food Chem 125: 1219-1225, 2011.

12. Dong M, Yang G, Liu H, Liu X, Lin S, Sun D and Wang Y: Aged black garlic extract inhibits HT29 colon cancer cell growth via the PI3K/Akt signaling pathway. Biomed Rep 2: 250-254, 2014.

13. Matsushima M, Kikuchi E, Matsumoto K, Hattori S, Takeda T, Kosaka T, Miyajima A and Oya M: Intravesical dual PI3K/mTOR complex 1/2 inhibitor NVP-BEZ235 therapy in an orthotopic bladder cancer model. Int J Oncol 47: 377-383, 2015.

14. Tahir AA, Sani NF, Murad NA, Makpol S, Ngah WZ and Yusof YA: Combined ginger extract \& Gelam honey modulate Ras/ERK and PI3K/AKT pathway genes in colon cancer HT29 cells. Nutr J 14: 31, 2015.

15. Majewska E and Szeliga M: AKT/GSK3 $\beta$ signaling in glioblastoma. Neurochem Res 42: 918-924, 2017
16. Yuyinng F: Research on phytic acid hydrolysis and the products of separation (D), 2010.

17. King EJ: The colorimetric determination of phosphorus. Biochem J 26: 292-297, 1932.

18. Rounds MA and Nielsen SS: Anion-exchange high-performance liquid chromatography with post-column detection for the analysis of phytic acid and other inositol phosphates. J Chromatogr A 653: 148-152, 1993.

19. Burbano C, Muzquiz M, Osagie A, Ayet G and Cuadrado C: Determination of phytate and lower inositol phosphates in Spanish legumes by HPLC methodology. Food Chem 52: 321-325, 1995.

20. Hong M, Li Z, Li SY and Yuan ZY: Preparation of inositol tetrakisphosphate and its application in modification of porcine hemoglobin. Sheng Wu Hua Xue Yu Sheng Wu Wu Li Xue Bao 32: 31-34, 2000.

21. Lehrfeld J: HPLC separation and quantitation of phytic acid and some inositol phosphates in foods: Problems and solutions. J Agric Food Chem 42: 2726-2731, 2002.

22. Sandberg AS, Carlsson NG and Svanberg U: Effects of inositol tri-, tetra-, penta-, and hexaphosphates on in vitro estimation of iron availability. J Food Sci 54: 159-161, 2006.

23. Suzuki T and Hara H: Phytate hydrolysate induces circumferential F-actin ring formation at cell-cell contacts by a Rho-associated kinase-dependent mechanism in colorectal cancer HT-29 cells. Mol Nutr Food Res 54: 1807-1818, 2010.

24. Sandberg AS and Ahderinne R: HPLC method for determination of inositol tri-, tetra-, penta-, and hexaphosphates in foods and intestinal contents. J Food Sci 51: 547-550, 1986.

25. Dinicola S, Fabrizi G, Masiello MG, Proietti S, Palombo A, Minini M, Harrath AH, Alwasel SH, Ricci G, Catizone A, et al: Inositol induces mesenchymal-epithelial reversion in breast cancer cells through cytoskeleton rearrangement. Exp Cell Res 345: 37-50, 2016.

26. Vucenik I and Shamsuddin AM: Cancer inhibition by inositol hexaphosphate $\left(\mathrm{IP}_{6}\right)$ and inositol: From laboratory to clinic. J Nutr 133 (Suppl 1): 3778S-3784S, 2003.

27. Vucenik I and Shamsuddin AM: Protection against cancer by dietary IP6 and inositol. Nutr Cancer 55: 109-125, 2006.

28. Bacić I, Druzijanić N, Karlo R, Skifić I and Jagić S: Efficacy of $\mathrm{IP}_{6}+$ inositol in the treatment of breast cancer patients receiving chemotherapy: Prospective, randomized, pilot clinical study. J Exp Clin Cancer Res 29: 12, 2010.

29. Schröterová L, Hasková P, Rudolf E and Cervinka M: Effect of phytic acid and inositol on the proliferation and apoptosis of cells derived from colorectal carcinoma. Oncol Rep 23: 787-793, 2010.

30. Kim JN, Han SN and Kim HK: Phytic acid and myo-inositol support adipocyte differentiation and improve insulin sensitivity in 3T3-L1 cells. Nutr Res 34: 723-731, 2014. 